\title{
Pengaruh Penambahan Doping Mn/Cu pada Barium Heksaferit sebagai Material Penyerap Gelombang
}

\author{
Silviana Simbolon ${ }^{1, *}$, Anggito P. Tetuko ${ }^{2}$, Candra Kurniawan ${ }^{1,2}$, \\ Perdamean Sebayang ${ }^{1,2}$, dan Krista Sebayang ${ }^{3}$
}

${ }^{1}$ Jurusan Teknik Mesin, Universitas Pamulang, Jl. Surya Kencana No 1, Tangerang Selatan, Banten, 15417
${ }^{2}$ Pusat penelitian Fisika LIPI, Kawasan Puspiptek Serpong, Tangerang Selatan, Banten, 15314
${ }^{3}$ Jurusan Fisika, Universitas Sumatera Utara, Jl. Bioteknologi, Padang Bulan, Sumatera Utara, 15314

E-mail: *simbolonsilvi@gmail.com

Masuk:9 November 2017 Direvisi : 21 November 2017 Disetujui : 4 Desember 2017

\begin{abstract}
Abstrak: Pada penelitian ini, telah dilakukan analisa efek doping $\mathrm{Mn}^{2+} / \mathrm{Cu}^{2+}$ sebanyak $0.1 \%$ mol terhadap struktur barium heksaferit sebagai material absorbsi gelombang mikro. Sintesis material dilakukan dengan metode mechanical alloying menggunakan planetary ball mill. Powder yang telah di-milling dikalsinasi pada temperature $1000{ }^{\circ} \mathrm{C}$ selama 2 jam. Powder hasil kalsinasi di kompaksi dengan tekanan $1.5 \mathrm{kgf} / \mathrm{cm}^{2}$ membentuk pellet dan di sinter pada temperatur $1150{ }^{\circ} \mathrm{C}$ selama 2 jam. Dari hasil eksperimen, menunjukkan penambahan ion $\mathrm{Mn}^{2+} / \mathrm{Cu}^{2+} 0.1 \%$ mol mengakibatkan nilai densitas bulk meningkat jika dibandingkan dengan barium heksaferit. Efek penambahan ion $\mathrm{Mn}^{2+} / \mathrm{Cu}^{2+}$ menurunkan nilai koersivitas ( $H j c)$ dan menaikkan nilai remanensi $(M r)$ yaitu $\mathrm{BaFe}_{12} \mathrm{O}_{19}$ memiliki $H j c=6.45 \mathrm{KOe}$ dan $M r=0.91 \mathrm{KG}, \mathrm{BaFe}_{11.9} \mathrm{Mn}_{0.1} \mathrm{O}_{19}$ memiliki $H j c=3.27 \mathrm{KOe}$ dan $M r=1.62 \mathrm{KG}$ sedangkan $\mathrm{BaFe}_{11.9} \mathrm{Cu}_{0.1} \mathrm{O}_{19}$ memiliki $H j c=1.75 \mathrm{KOe}$ dan $M r=1.79 \mathrm{KG}$. Pengukuran refflection loss gelombang mikro menggunkan VNA menunjukkan bahwa penambahan ion $\mathrm{Mn}^{2+} / \mathrm{Cu}^{2+}$ pada barium heksaferit memiliki rentang frekuensi yang berbeda. Frekuensi $\mathrm{BaFe}_{11.9} \mathrm{Mn}_{0.1} \mathrm{O}_{19}$ sekitar $4-10 \mathrm{GHz}$ dan $\mathrm{BaFe}_{11.9} \mathrm{Cu}_{0.1} \mathrm{O}_{19}$ sekitar $4-8 \mathrm{GHz}$. Hal ini menunjukkan bahwa besar penyerapan gelombang yang cukup signifikan dengan adanya penambahan doping $\mathrm{Mn} / \mathrm{Cu} 0.1 \%$ mol jika dibandingkan terhadap barium hexaferit.
\end{abstract}

Kata kunci: Barrium Hexaferrite, Ion $\mathrm{Mn} / \mathrm{Cu}$, absorber

\begin{abstract}
In this study, the effect of $0.1 \% \mathrm{~mol} \mathrm{Mn} / \mathrm{Cu}$ dopants on barium hexaferrite structure as microwave absorbing materials have been investigated. The material synthesis was performed by mechanical alloying method using planetary ball mill. The milled powder was calcined at the temperature of $1000^{\circ} \mathrm{C}$ for 2 hours. The calcined powder was compacted in the pressure of $1.5 \mathrm{kgf} / \mathrm{cm}^{2}$ then sintered at the temperature of $1150^{\circ} \mathrm{C}$ for 2 hours. From the experimental results, we observed that the addition of $0.1 \% \mathrm{~mol} \mathrm{Mn} / \mathrm{Cu}$ ion generally increases bulk density rather than bulk density of barriumhexaferrite. The magnetic characterization shows that $\mathrm{Mn} / \mathrm{Cu}$ ions doped decrease the coercivity and increase the magnetic remanence that $\mathrm{BaFe}_{12} \mathrm{O}_{19}$ has $\mathrm{Hjc}=1.75$ and $\mathrm{Mr}=1.79 \mathrm{KG}$. The microwave reflection loss analysis was used by $\mathrm{VNA}$ measurement that the addition of $\mathrm{Mn}^{2+} / \mathrm{Cu}^{2+}$ ions on barium hexaferrite have different absorbing frequency regime. The $B a F e_{12-x} M_{x} O_{19}$ frequency is round $4-10 \mathrm{GHz}$ and the $\mathrm{BaFe}_{12-x} \mathrm{Cu}_{x} \mathrm{O}_{19}$ frequency is around $4-12 \mathrm{GHz}$. It showed that the significant of wave absorbtion with the addition of $\mathrm{Mn}^{2+} / \mathrm{Cu}^{2+} 0.1 \%$ if compared barium hexaferrite.
\end{abstract}

Keywords: Barium Hexaferrite, $\mathrm{Mn}, \mathrm{Cu}$, absorber

\section{PENDAHULUAN}

Material barium heksaferittermasuk bahan keramik yang merupakan bahan magnetik. Material ini memiliki karakteristik: temperatur Curie, koersivitas, saturasi magnetik dan anisotropi magnetik yang relative tinggi serta stabilitas kimia yang sangat baik [1-5]. Material barium heksaferit merupakan magnet permanen yang dapatdiaplikasikan dalam berbagai bidang sebagai hard magnetik. Material ini juga dapat dibuat menjadi soft magnetik dengan tambahan doping sebagai material penyerap gelombang radaryang sangat baik. Hal ini karena sifat listrik dan magnetik dari material ferrimagnetik ini sangat mendukung dalam aplikasi tersebut, yaitu 
memiliki permeabilitas dan resistivitas yang tinggi [6]. Barium Heksaferrit dapat disintesis dengan metode kristalisasi gas, presipitasi hidrotermal, sol-gel, aerosol, pemanduan mekanik dan kopresipitasi [7].

Menurut penelitian H. Sözeri et.al telah melakukan analisis dan karakterisasi sifat elektromagnetik barium heksaferit yang diberikan bahan doping $\left(\mathrm{M}=\mathrm{Mn}^{2+}\right.$ dan $\left.\mathrm{Zn}^{2+}\right)$ sebanyak $1 \%$ molsebagai penyerap gelombang mikro pada daerah rentang frekuensi 4-15 GHz. Hasil yang diperoleh menunjukkan bahwaminimum reflection loss (RL) $10 \mathrm{~dB}$ pada frekuensi $15 \mathrm{GHz}$ dan untuk sampel dengan doping $\mathrm{Zn}$ dan Mn mampu mencapai $10 \mathrm{~dB}$ pada frekuensi $4 \mathrm{GHz}$ [5].

Dalam penelitian ini akan membahas dan membandingkan hasil dari modifikasi material barium heksaferit sebagai hard magnetik menjadi soft magnetik dengan penambahan doping $\mathrm{Mn}^{2+} / \mathrm{Cu}^{2+}$. fungsi doping $\mathrm{Mn}^{2+} / \mathrm{Cu}^{2+}$ untuk mensubsitusi ion Fe. (Fungsi $\mathrm{Mn}^{2+} / \mathrm{Cu}^{2+}$ ). Sumber bahan $\mathrm{Mn}^{2+}$ diperoleh dari mangan oksida $(\mathrm{MnO})$ dan $\mathrm{Cu}^{2+}$ dari tembaga oksida $(\mathrm{CuO})$. Penambahan doping $\mathrm{Mn}^{2+} / \mathrm{Cu}^{2+}$ bertujuan menurunkan sifat magnetik dan menaikkan nilai saturasi dari barium heksaferit. Hal ini dikarenakan sifat paramagnetik dari doping $\mathrm{Mn}^{2+} / \mathrm{Cu}^{2+}$. Hal tersebut akan meningkatkan sifat adsorber pada barium heksaferit sebagai material penyerap gelombang[5].Pada proses pembuatan material ini menggunakan metode mechanical alloying yang dikalsinasi pada suhu $1000{ }^{\circ} \mathrm{C}$ dan dilajutkan proses sintering $1150^{\circ} \mathrm{C}$, masing - masing ditahan selama 2 jam. Karakterisasi yang dilakukan meliputi: analisa X-Ray Diffraction,pengukuran nilai densitas, morfologi material menggunakan Scanning Electron Microscope (SEM), sifat magnetik menggunakan permagraf, dan pengukuran reflection loss menggunakan VNA.

\section{METODOLOGI}

Preparasi bahan magnetik barium heksaferit dengan penambahan ion $\mathrm{Mn}^{2+} / \mathrm{Cu}^{2+}$ menggunakan bahan baku $\mathrm{BaCO}_{3}, \mathrm{Fe}_{2} \mathrm{O}_{3}, \mathrm{MnO}$ dan $\mathrm{CuO}$. Kemudian bahan - bahan baku tersebut dicampur dengan metode mechanical alloying menggunakan Planetary Ball Milling (PBM) secara wet milling selama 20 jam. Bahan baku yang telah digiling tersebut dikeringkan pada $100{ }^{\circ} \mathrm{C}$ selama 24 jam agar kandungan air terurai. Serbuk yang dikeringkan dikalsinasi pada suhu $1000{ }^{\circ} \mathrm{C}$, ditahan selama 2 jam untuk membentuk fasa barium heksaferit. Serbuk barium heksaferit yang terbentuk digiling menggunakan mortal hingga mencapai ukuran butir 400 mesh. Kemudian dicampur dengan perekat polimer Celuna WE - 518 sebanyak 3\% (berat) dan dikompaksi dengan tekanan tekanan $1,5 \mathrm{tonf} / \mathrm{cm}^{2}$ untuk membentuk pelet dengan dimensi diameter $20 \mathrm{~mm}$ dan tebal $10 \mathrm{~mm}$. Sampel yang terbentuk disintering dengan temperatur $1150^{\circ} \mathrm{C}$ selama 2 jam.

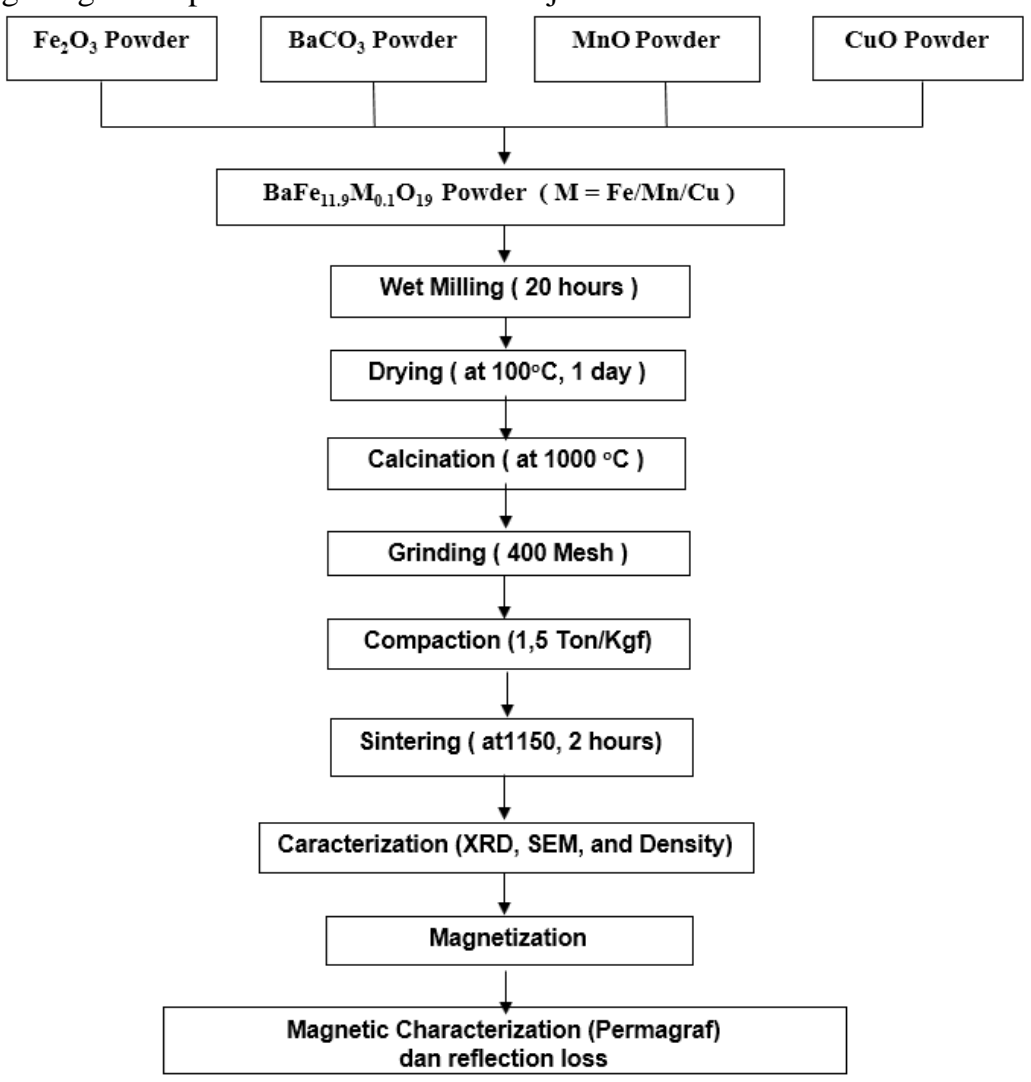

Gambar 1. Skema pembuatan sampel $\mathrm{BaFe}_{11.9} \mathrm{M}_{0.1} \mathrm{O}_{19}$, dimana $(\mathrm{M}=\mathrm{Fe}, \mathrm{Mn}$, dan $\mathrm{Cu})$. 


\section{HASIL DAN PEMBAHASAN}

Pada Gambar 2, diketahui bahwa telah terbentuk 2 phasa yakni barium heksaferite dan hematit yang terbentuk saat proses kalsinasi pada suhu $1000{ }^{\circ} \mathrm{C}$ ditahan selama 2 jam. Dimana phasa dominan dimiliki oleh barium heksaferit dan minor merupakan hematit yang terbentuk sebagai pengotor [8].

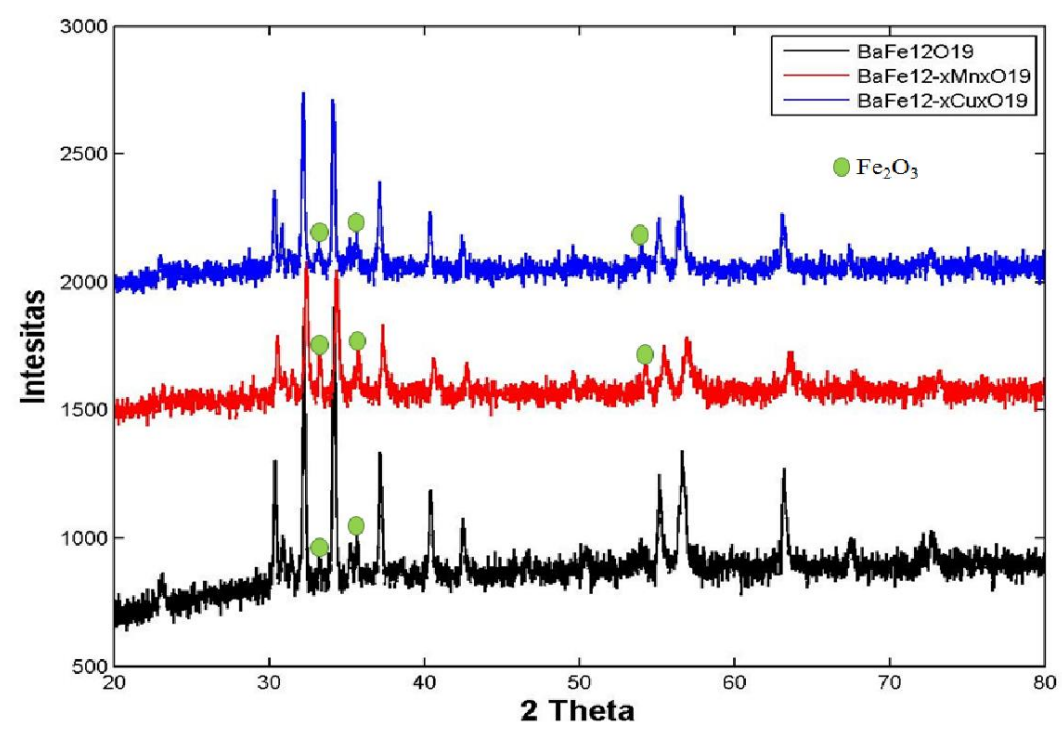

Gambar 2. Hasil XRD sampel $\mathrm{BaFe}_{11.9} \mathrm{M}_{0.1} \mathrm{O}_{19}$, dimana $(\mathrm{M}=\mathrm{Fe}, \mathrm{Mn}$, dan $\mathrm{Cu})$.

Pada Tabel 1, juga dapat diketahui adanya pergeseran parameter kisi pada phasa barium hexaferite dengan adanya penambahan ion $\mathrm{Mn}^{2+} / \mathrm{Cu}^{2+}$ sebesar $0.1 \%$ mol. Hal ini menunjukkan telah terjadi subsitusi ion $\mathrm{Mn}^{2+} / \mathrm{Cu}^{2+}$ terhadap ion Fe[5]. Penurunan nilai intensitas juga terlihat dengan penambahan ion $\mathrm{Mn}^{2+} / \mathrm{Cu}^{2+}$.

Tabel 1. Parameter kisi sampel $\mathrm{BaFe}_{11.9} \mathrm{M}_{0.1} \mathrm{O}_{19}$, dimana $(\mathrm{M}=\mathrm{Fe}, \mathrm{Mn}$, dan $\mathrm{Cu})$.

\begin{tabular}{ccc}
\hline \multirow{2}{*}{ Sampel } & \multicolumn{2}{c}{ Parameter Kisi } \\
\cline { 2 - 3 } & $\mathrm{a}(\AA)$ & $\mathrm{c}(\AA)$ \\
\hline $\mathrm{BaFe}_{12} \mathrm{O}_{19}$ & 5.892 & 23.183 \\
$\mathrm{BaFe}_{11.9} \mathrm{Mn}_{0.1} \mathrm{O}_{19}$ & 5.893 & 23.201 \\
$\mathrm{BaFe}_{11.9} \mathrm{Cu}_{0.1} \mathrm{O}_{19}$ & 5.865 & 23.099 \\
\hline
\end{tabular}

Pada Tabel 2, Ditunjukkan hasil pengukuran densitas pada barium heksaferit dalam bentuk pellet setalah di sinter pada suhu $1150{ }^{\circ} \mathrm{C}$. Kenaikan nilai densitas sangat dipengaruh oleh proses sinter dan penambahan ion $\mathrm{Mn}^{2+} / \mathrm{Cu}^{2+}$ jika dibandingkan dengan nilai densitas barium heksaferit, $\mathrm{BaFe}_{11.9} \mathrm{Mn}_{0.1} \mathrm{O}_{19}=4,67 \mathrm{~g} / \mathrm{cm}^{3}$, $\mathrm{BaFe}_{11.9} \mathrm{Cu}_{0.1} \mathrm{O}_{19}=3,8 \mathrm{~g} / \mathrm{cm}^{3}$, dan pure $\mathrm{BaFe}_{12} \mathrm{O}_{19}=3.13 \mathrm{~g} / \mathrm{cm}^{3}$. Hal ini menunjukkan telah terjadi proses pemadatan pada proses sinter dan adanya pengaruh perbedaan nilai true density $\mathrm{Fe}=7,87 \mathrm{~g} / \mathrm{cm}^{3}, \mathrm{Mn}=7,47$ $\mathrm{g} / \mathrm{cm}^{3}$ dan $\mathrm{Cu}=8,92 \mathrm{~g} / \mathrm{cm}^{3}$.

Tabel 2. Pengaruh ion $\mathrm{Mn}^{2+} / \mathrm{Cu}^{2+}$ terhadap nilai densitas pada pellet barium hexaferrite.

\begin{tabular}{cc}
\hline \multicolumn{1}{c}{ Sampel } & Densitas $\left(\mathrm{g} / \mathrm{cm}^{3}\right)$ \\
\hline $\mathrm{BaFe}_{12} \mathrm{O}_{19}$ & 3.13 \\
$\mathrm{BaFe}_{11.9} \mathrm{Cu}_{0.1} \mathrm{O}_{19}$ & 3.8 \\
$\mathrm{BaFe}_{11.9} \mathrm{Mn}_{0.1} \mathrm{O}_{19}$ & 4.67 \\
\hline
\end{tabular}

Gambar struktur permukaan pure barium heksaferite dan dengan penambahan ion $\mathrm{Mn}^{2+} / \mathrm{Cu}^{2+}$ ditunjukkan pada Gambar 3. Pada Gambar 3(a) Terlihat distribusi porositi yang cukup banyak dan lebar pada permukaan pure barium heksaferite.Sedangkan pada penambahan ion $\mathrm{Mn}^{2+}$ terlihat adanya penurunan yang signifikan terhadap distribusi porosity meskipun masih terdapat celah poros yang cukup lebar pada permukaan sampel, Gambar 3(b). pada penambahan ion $\mathrm{Cu}^{2+}$, permukaan barium heksaferit terlihat menggumpal namun masih 
memiliki banyak porositas yang besar, hal ini ditunjukkan pada Gambar 3(c). Diduga selama proses reaksi dan densifikasi, dapat terjadi proses sintering reaktif yang biasanya menghasilkan porositas pada permukaan sampel. Berbagai reaksi yang mungkin terjadi pada saat sintering reaktif seperti reaksi oksidasi - reduksi dan tahap transisi. Dengan cara ini reaksi yang disebabkan oleh kotoran, aditif atau produk lainnya terbentuk selama proses sintering [9].

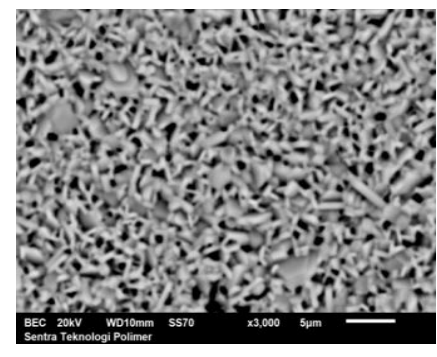

(a)

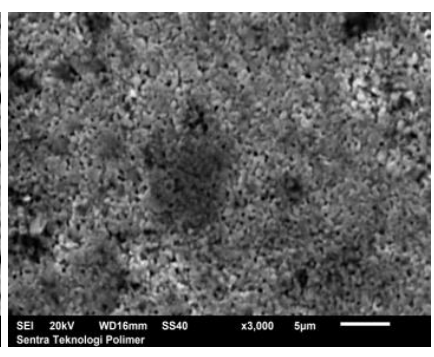

(b)

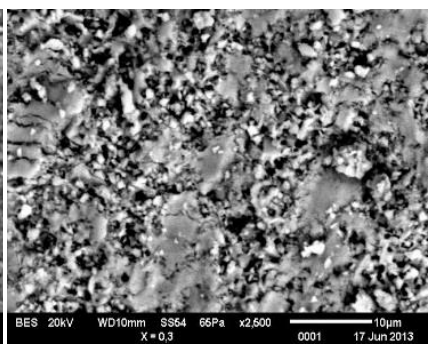

(c)

Gambar 3. Morfologi permukaan sampel setelah proses sintering, distribusi dan ukuran pori menggunakan SEM perbesaran 3.000x pada sampel a) $\mathrm{BaFe}_{12} \mathrm{O}_{19}$, b) $\mathrm{BaFe}_{11.9} \mathrm{Mn}_{0.1} \mathrm{O}_{19}$ dan c) $\mathrm{BaFe}_{11.9} \mathrm{Cu}_{0.1} \mathrm{O}_{19}$.

Pada pengukuran sifat magnet menggunakan pemagraf, ditunjukkan pada Gambar 4, bahwa terdapat perbedaan yang signifikan terhadap sifat magnet barium heksaferit dengan dilakukannya penambahan ion $\mathrm{Mn}^{2+} / \mathrm{Cu}^{2+}$. Penurunan koersivitas dan meningkatnya nilai remanensi sebagai pengaruh ion $\mathrm{Mn}^{2+} / \mathrm{Cu}^{2+}$ terhadap barium hexaferite, $\mathrm{BaFe}_{12} \mathrm{O}_{19}=6.45 \mathrm{KOe}, \mathrm{BaFe}_{11.9} \mathrm{Mn}_{0.1} \mathrm{O}_{19}=3.27 \mathrm{KOe}$, dan pure $\mathrm{BaFe}_{11.9} \mathrm{Cu}_{0.1} \mathrm{O}_{19}=1.75 \mathrm{KOe}$. Hal ini terjadi akibat dari karakteristik ion $\mathrm{Mn}^{2+} / \mathrm{Cu}^{2+}$ yang paramagnetik mempengaruhi sifat barium heksaferit yang merupakan hard magnetik permanent menjadi semi- soft magnetik dengan penambahan $0.1 \%$ mol ion $\mathrm{Mn}^{2+} / \mathrm{Cu}^{2+}[10]$.

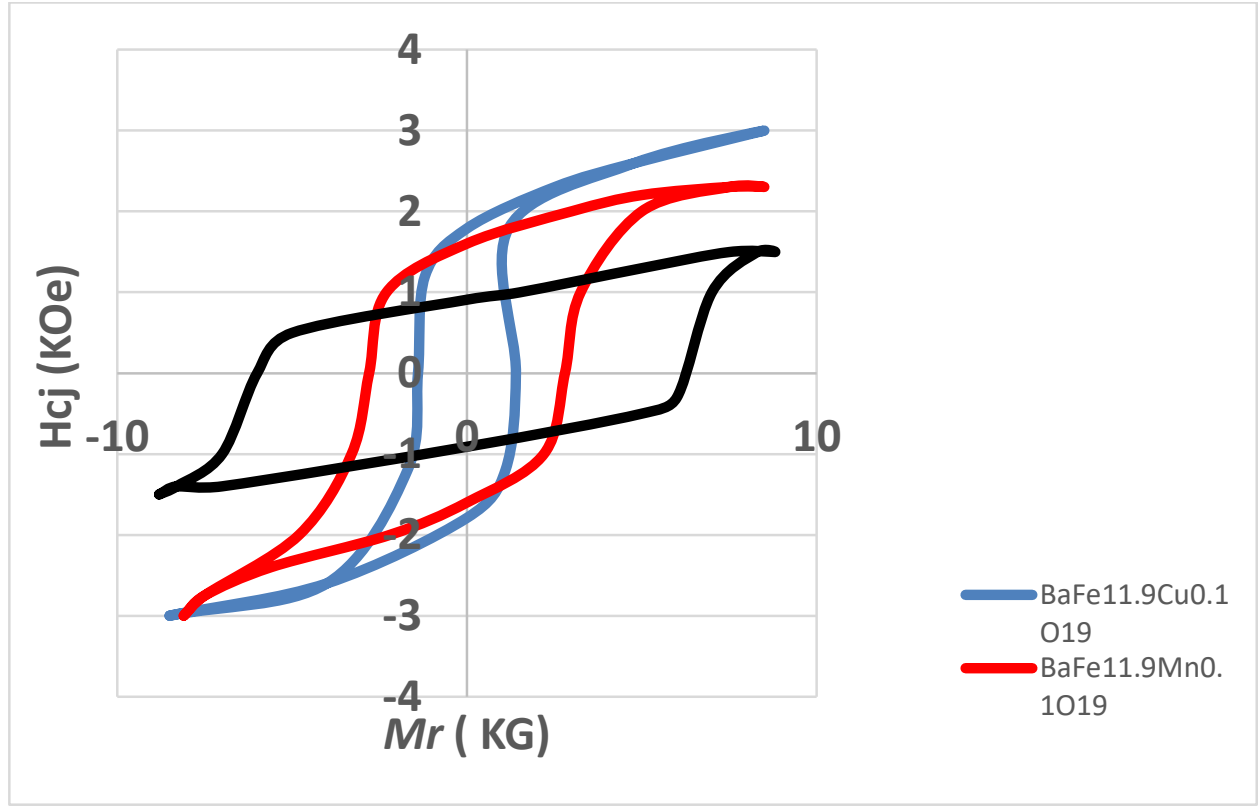

Gambar 4. Grafik histerisis dari sampel $\mathrm{BaFe}_{11.9} \mathrm{M}_{0.1} \mathrm{O}_{19}$, dimana $(\mathrm{M}=\mathrm{Fe}, \mathrm{Mn}$, dan $\mathrm{Cu})$.

Penurunan sifat magnetik barium heksaferit setelah dilakukan penambahan ionMn ${ }^{2+} / \mathrm{CU}^{2+}$ dari hard magnetik menjadi semi soft magnetik diharapkan mampu meningkatkan hasil penyerapan gelombang micro $\mathrm{X}-$ band [11]. Ini terlihat pada Gambar 5, menunjukkan bahwa penambahan ion $\mathrm{Mn}^{2+} / \mathrm{CU}^{2+}$ pada barium heksaferit memiliki lebar frekuensi yang berbeda. Frekuensi $\mathrm{BaFe}_{11.9} \mathrm{Mn}_{0.1} \mathrm{O}_{19}$ sekitar 4 - $10 \mathrm{GHz}$ dan $\mathrm{BaFe}_{11.9} \mathrm{Cu}_{0.1} \mathrm{O}_{19}$ sekitar $4-8 \mathrm{GHz}$ dan penyerapan gelombang yang cukup signifikan dengan adanya penambahan ion $\mathrm{Mn}^{2+} / \mathrm{Cu}^{2+}$ $0.1 \%$ mol jika dibandingkan terhadap barium hexaferit.Ini membuktikan adanya kontribusi peranan ion $\mathrm{Mn}^{2+}$ dan $\mathrm{Cu}^{2+}$ dalam mempengaruhi sifat absorber magnet permanen barium heksaferit sebagai material absorber gelombang mikro. Dari hasil uji VNA, didapatkan nilai refflection loss untuk $\mathrm{BaFe}_{11.9} \mathrm{Mn}_{0.1} \mathrm{O}_{19}$ mencapai $23 \mathrm{~dB}$ sedangkan $\mathrm{BaFe}_{11.9} \mathrm{Cu}_{0.1} \mathrm{O}_{19}$ mencapai $25,3 \mathrm{~dB}$. 


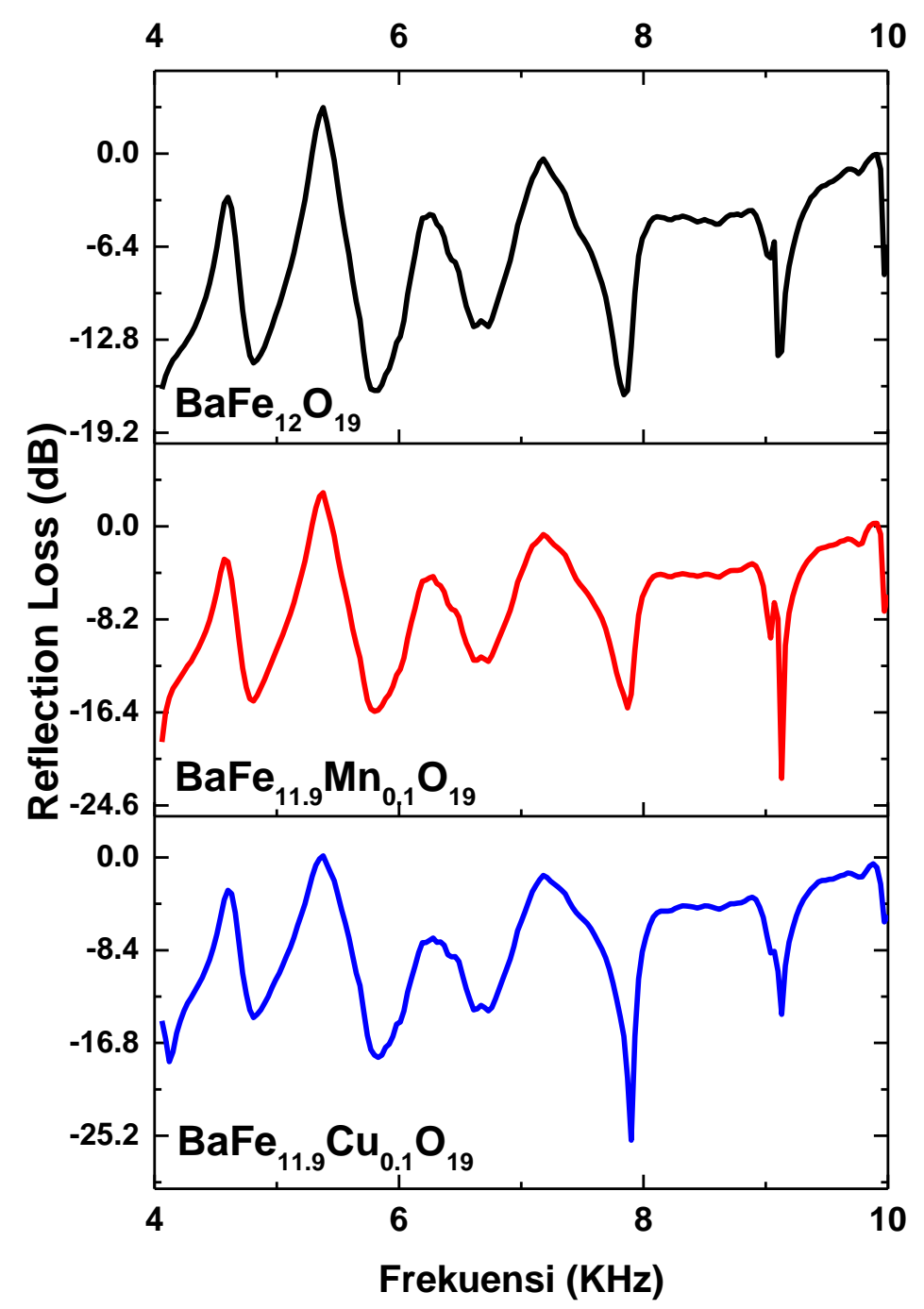

Gambar 5. Grafik Reflection Loss dengan frekuensi untuk sampel $\mathrm{BaFe}_{11.9} \mathrm{M}_{0.1} \mathrm{O}_{19}$, dimana $(\mathrm{M}=\mathrm{Fe}, \mathrm{Mn}$, dan $\mathrm{Cu})$.

\section{KESIMPULAN}

Telah berhasil dilakukan sintesis dan investigasi efek penambahan ion $\mathrm{Mn}^{2+} / \mathrm{Cu}^{2+}$ terhadap struktur barium heksaferit sebagai material absorbsi gelombang mikro. Kenaikan jumlah ion $\mathrm{Mn}^{2+} / \mathrm{Cu}^{2+}$ menaikkan densitas bulk Jika dibandingkan dengan pellet barium heksaferit. dari hasil karakterisasi sifat magnet material,penambahan ion $\mathrm{Mn} / \mathrm{Cu}$ menurunkan nilai koersivitas dan menaikkan nilai remanensi. Hal ini menunjukkan perubahan sifat struktur barium heksaferit dari hard menjadi semi-soft magnetik dengan penambahan ion $\mathrm{Mn}^{2+} / \mathrm{Cu}^{2+}$. Hasil VNA diketahui bahwa penambahan ion $\mathrm{Mn}^{2+} / \mathrm{Cu}^{2+}$ pada barium heksaferit memiliki nilai refflection lossdan lebar frekuensi yang berbeda. Pada penelitian ini didapatkan komposisi terbaik dipelihatkan pada sampel $\mathrm{BaFe}_{11.9} \mathrm{Cu}_{0.1} \mathrm{O}_{19}$ denganpenambahan ion $\mathrm{Cu}$ pada barium heksaferit, dengan nilai refflection loss $25,3 \mathrm{~dB}$ pada frekuensi $<8 \mathrm{GHz}$. 
40 | Silviana Simbolon, dkk., Pengaruh Penambahan Doping Mn/Cu...,

\section{DAFTAR PUSTAKA}

[1] Dhage V N, Mane M L, Keche A P, Birajdar C T dan Jadhav K M 2011 Phys. B: Condens. Matter 406789

[2] Dehlinger A S, Le Berre M, Canut B, Chatelon J P, Albertini D, Perrot S, Givord D dan Rousseau J J 2010 J. Magn. Magn. Mater. 3223293

[3] Topal U dan Bakan H I 2010 J. Eur. Ceram. Soc. 303167

[4] Xu H, Zhang W, Peng B dan Zhang W 2011 Appl. Surf. Sci. 2572689

[5] Birs “ oz B, Baykal A, S“ ozeri H dan Toprak M S 2010 J. Alloys Compd. 493481

[6] Priyono 2010 Karakteristik Magnetik dan Absorbsi Gelombang Mikro Material Magnet Berbahan Dasar Barium Hexaferrite (Jakarta: Universitas Indonesia)

[7] Kosasih, A. Noly, dkk. 2006 Sintesis Dan Karakterisasi Sifat Magnetik Serbuk Barium M-Heksa ferrit Dengan Doping Ion Zn Pada Variasi Temperatur Rendah. Fisika, Fakultas Matematika dan Ilmu Pengetahuan Alam, Institut Teknologi Sepuluh Nopember (ITS).

[8] Costaa A C F M, Diniz A P, Silvaa V J, Kiminami R H G A, Cornejoc D R, Gama A M, Rezende M C dan Gamaa L 2009 Journal of Alloys and Compounds 483563

[9] Wismogroho A S 2013 Pengembangan Dilatometer Untuk Analisa Karakteristik Sintering Magnet Basis Ferrite (Jakarta: Pusat Penelitian Fisika - LIPI)

[10] Coker E G, Yetgin N, Yildiz E, Alikma F, Acar E dan Topal U 2013 J. Supercond. Nov. Magn. 261011

[11] Gairola S P, Vermaa V, Singh A, Purohit L P dan Kotnala R K 2010 Solid State Communications 150147 